\title{
CÁPSULA ENDOSCÓPICA DE COLON VERSUS COLONOSCOPIA EN EL CRIBADO FAMILIAR DE CANCER COLORRECTAL
}

Cristina Alvarez Urturi

Directora: Begoña Gonzalez Suarez

Colaboradores: Inés Ibañez, Xavier Bessa Caserras, Josep Mª Dedeu Cusco, Montserrat Andreu Garcia

Servicio de Digestivo, Hospital del Mar, Barcelona.

Trabajo de investigación, Departamento de Medicina, Universitat Autònoma de Barcelona.

Junio 2010 


\section{CERTIFICAT DEL DIRECTOR O CO-DIRECTOR DEL TREBALL \\ DE RECERCA}

Dra. Begoña González Suárez, Professora Associada del Departament de Medicina UAB

FA CONSTAR,

que el treball titulat "CAPSULA ENDOSCÓPICA DE COLON VERSUS

COLONOSCOPIA EN EL CRIBADO FAMILIAR DE CANCER COLORRECTAL"

ha estat realitzat sota la meva direcció pel Ilicenciat Cristina Alvarez Urturi , trobant-se en condicions de poder ser presentat com a treball d'investigació de 12 crèdits, dins el programa de doctorat en Medicina Interna/Diagnòstic per la Imatge (curs 2009-2010), a la convocatòria de juny.

Barcelona, maig de dos mil deu. 


\title{
PALABRAS CLAVE
}

Cápsula endoscópica, cáncer colorrectal.

\author{
PARAULAS CLAU
}

Càpsula endoscòpica, càncer colorrectal.

\section{RESUMEN}

Los objetivos fueron evaluar prospectivamente la capacidad diagnóstica de la cápsula endoscópica comparada con colonoscopia en 30 pacientes con historia familiar de CCR, y evaluar la limpieza colónica con preparación mediante Moviprep. La prevalencia de pólipos detectados por cápsula y colonoscopia fue de $20,7 \%$ y $24,1 \%$. La sensibilidad y especificidad en detección de pólipos fue de $71,4 \%$ y $95,4 \%$, respectivamente, con VPP y VPN de 83,3 y $91,3 \%$. Se concluye que la cápsula endoscopica ofrece una técnica alternativa precisa, fiable, bien tolerada y segura para el cribado familiar de CCR.

\section{RESUM}

Els objectius van ser avaluar prospectivament la capacitat diagnòstica de la càpsula endoscòpica en comparació amb la colonoscòpia en 30 pacients amb història familiar de CCR, i avaluar la neteja colònica amb preparació amb Moviprep. La prevalença de pòlips detectats amb càpsula i colonoscòpia va ser de $20,7 \%$ i $24,1 \%$, respectivament. La sensibilitat i especificitat en detecció de pòlips va ser de 71, 4 i 95,4\%, respectivament, amb VPP i VPN de 83,3 i $91,3 \%$. Es conclou que la càpsula endoscòpica suposa una tècnica alternativa precisa, fiable, ben tolerada i segura pel cribatge familiar de CCR. 


\section{INDEX}

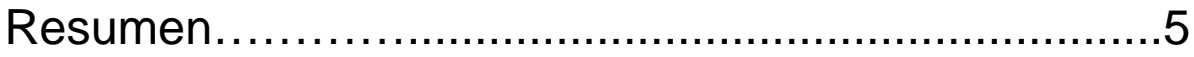

Introducción........................................................

Epidemiologia

Cribado en el CCR familiar

Pruebas de cribado

Cápsula endoscópica

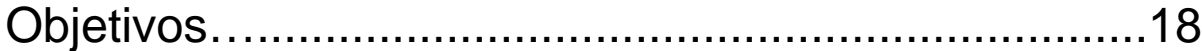

Material y métodos................................................19

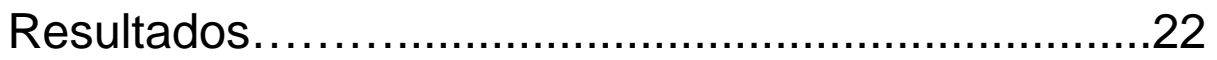

Características generales

Historia familiar CCR

Limpieza del colon

Hallazgos endoscópicos

Tasa de excreción

Efectos adversos

Grado de satisfacción

Discusión..........................................................28

Conclusiones.......................................................

Anexos.................................................................

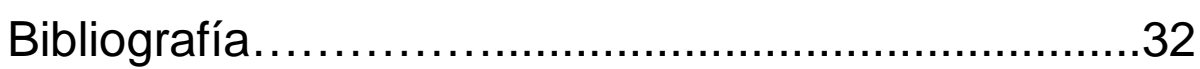




\section{RESUMEN}

INTRODUCCIÓN: Los pacientes con historia familiar de cáncer colorrectal (CCR) presentan un riesgo aumentado de presentar CCR. La cápsula endoscópica es una potencial herramienta para el cribado de CCR. Los objetivos del estudio fueron evaluar la capacidad diagnóstica de la cápsula endoscópica en comparación con la colonoscopia en pacientes con historia familiar de CCR, así como evaluar la limpieza colónica tras preparación intestinal con Moviprep.

MATERIAL Y MÉTODOS: Se realizó un estudio prospectivo y unicéntrico en una cohorte de pacientes con historia familiar de CCR. Todos los pacientes realizaron una limpieza colónica exhaustiva con Moviprep. La cápsula endoscópica y la colonoscopia se realizaron el mismo día, por endoscopistas ciegos para el otro resultado. Se recogieron datos demográficos, limpieza del colon, hallazgos endoscópicos y grado de satisfacción de cada método, asi como los posibles efectos adversos.

RESULTADOS: Se incluyeron 30 pacientes. Un paciente no se incluyó en el análisis final por abandono del estudio. La edad media fue de 47,9 años. Todos los pacientes tenían un familiar de primer grado diagnosticado de CCR antes de los 60 años de edad, o dos ó mas familiares de primer o segundo grado diagnosticados a cualquier edad. Todos los pacientes tuvieron excelente tolerancia a la preparación. La limpieza global colónica fue aceptable, buena o excelente en el $79,3 \%$ de los casos. La prevalencia de pólipos detectados por cápsula y colonoscopia fue de $20,7 \%$ y $24,1 \%$ respectivamente. La sensibilidad y especificidad para la detección de pólipos de cualquier tamaño fue de $71,4 \%$ y $95,4 \%$, respectivamente, con VPP y VPN de 83,3 y $91,3 \%$; mientras que para la detección de pólipos significativos, definidos como iguales o mayores a $6 \mathrm{~mm}$ de tamaño, la $S$ y E fueron de 100 y 89\%, con VPP y VPN de 66 y 100\%. No se encontraron diferencias en la detección de pólipos según el grado de limpieza.

CONCLUSIÓN: La cápsula endoscopica ofrece una técnica alternativa precisa, fiable, bien tolerada y segura para el cribado familiar de CCR. La preparación con Moviprep permite un grado de limpieza aceptable, bueno o excelente en la mayoría de los pacientes, con excelente tolerancia. 


\section{INTRODUCCIÓN}

\section{EPIDEMIOLOGIA}

El cáncer colorrectal (CCR) representa la segunda causa de muerte por cáncer en España, registrándose más de 11.000 muertes por año. Se trata de la segunda neoplasia más frecuente, después del cáncer de pulmón en el hombre y del cáncer de mama en la mujer, pero ocupa el primer lugar si no se hace distinción de sexo, detectándose actualmente más de 25.000 nuevos casos al año ${ }^{1}$, de los cuales casi el 50\% fallecerá por la enfermedad.

La incidencia de cáncer de colon es 3 veces superior a la de recto, aunque las cifras de cáncer de colon y recto varían entre los diferentes registros.

Incidencia y mortalidad de CCR en la Unión Europea en 2002:

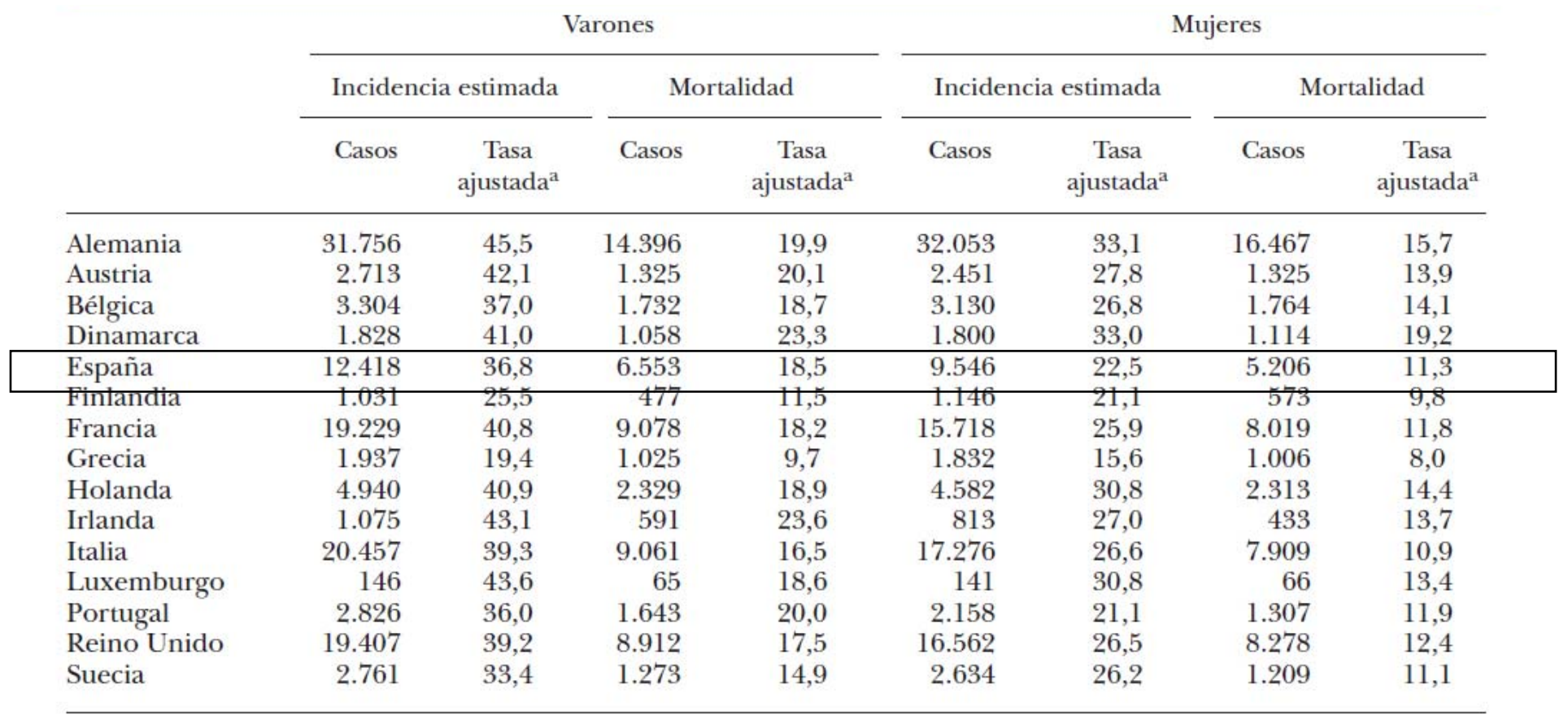

\footnotetext{
aTasa ajustada por población mundial por 100.000 habitantes.
}

Fuente: Globocan 2002 (http://www-dep.iarc.fr/) 
Los registros de CCR muestran una tendencia al aumento, más marcada en varones que en mujeres. Este aumento del número de casos observados está influenciado en gran medida por el progresivo envejecimiento de la población, siendo el riesgo medio de padecer CCR a lo largo de la vida del 5$6 \%$ en países occidentales.

La incidencia de CCR varía en función de la edad, observándose un aumento notorio a partir de los 50 años.

Incidencia de cáncer de colon y recto en España en 2002 (varones y mujeres):

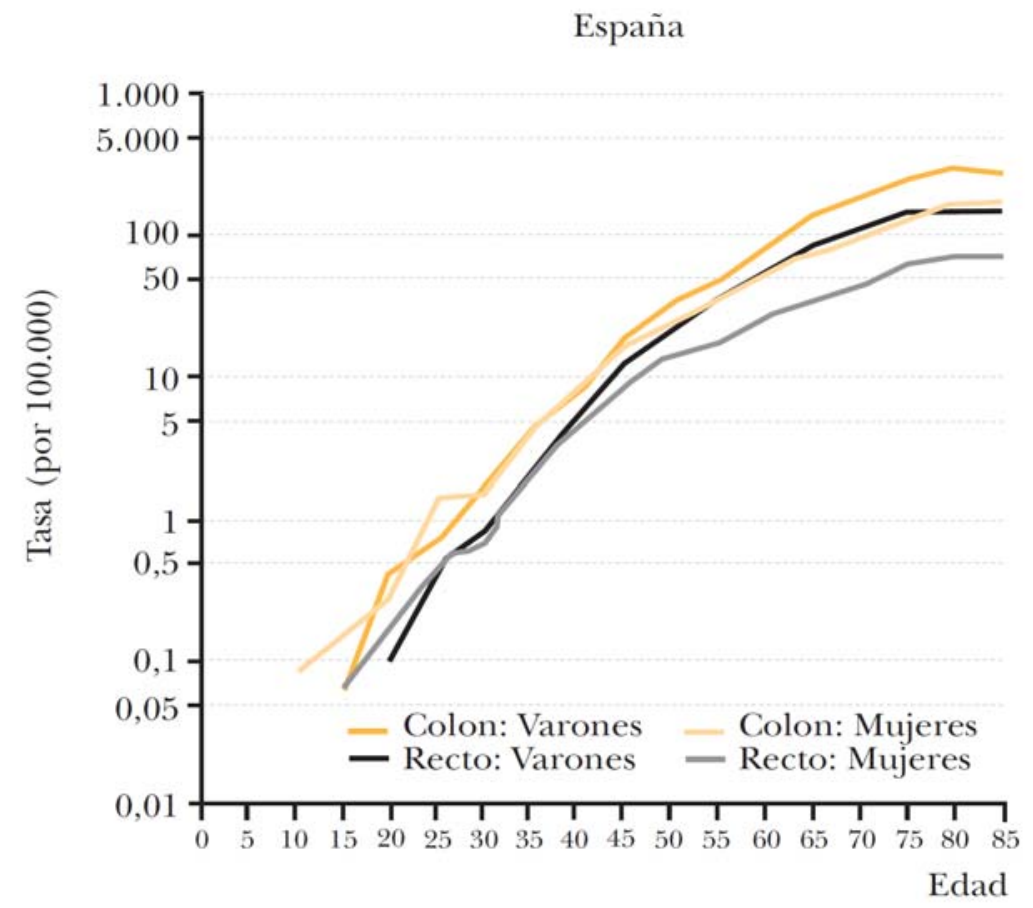

La mayoría de casos de CCR son casos esporádicos, mientras que una pequeña proporción corresponde a formas familiares: poliposis adenomatosa familiar (PAF) en menos de 1\% de los casos, o síndrome de Lynch (2-5\%). Se estima que en el 15-20\% puede haber un componente hereditario todavía no bien establecido.

Respecto a la distribución anatómica, varía según las series; la localización más frecuente es recto y sigma, siendo menos frecuentes otras localizaciones (colon ascendente, ciego, ángulo hepático, colon transverso y ángulo esplénico). 
En España, en el año 2006 se produjeron 7903 muertes por CCR en varones, y 5490 en mujeres, lo que representa un $12,4 \%$ de las muertes por cáncer en varones, y $9,6 \%$ en mujeres.

En los últimos años, la mortalidad por CCR muestra una tendencia a la disminución, que podría estar relacionada con la mejora en el diagnóstico y tratamiento del CCR.

Supervivencia de pacientes con CCR (varones y mujeres)

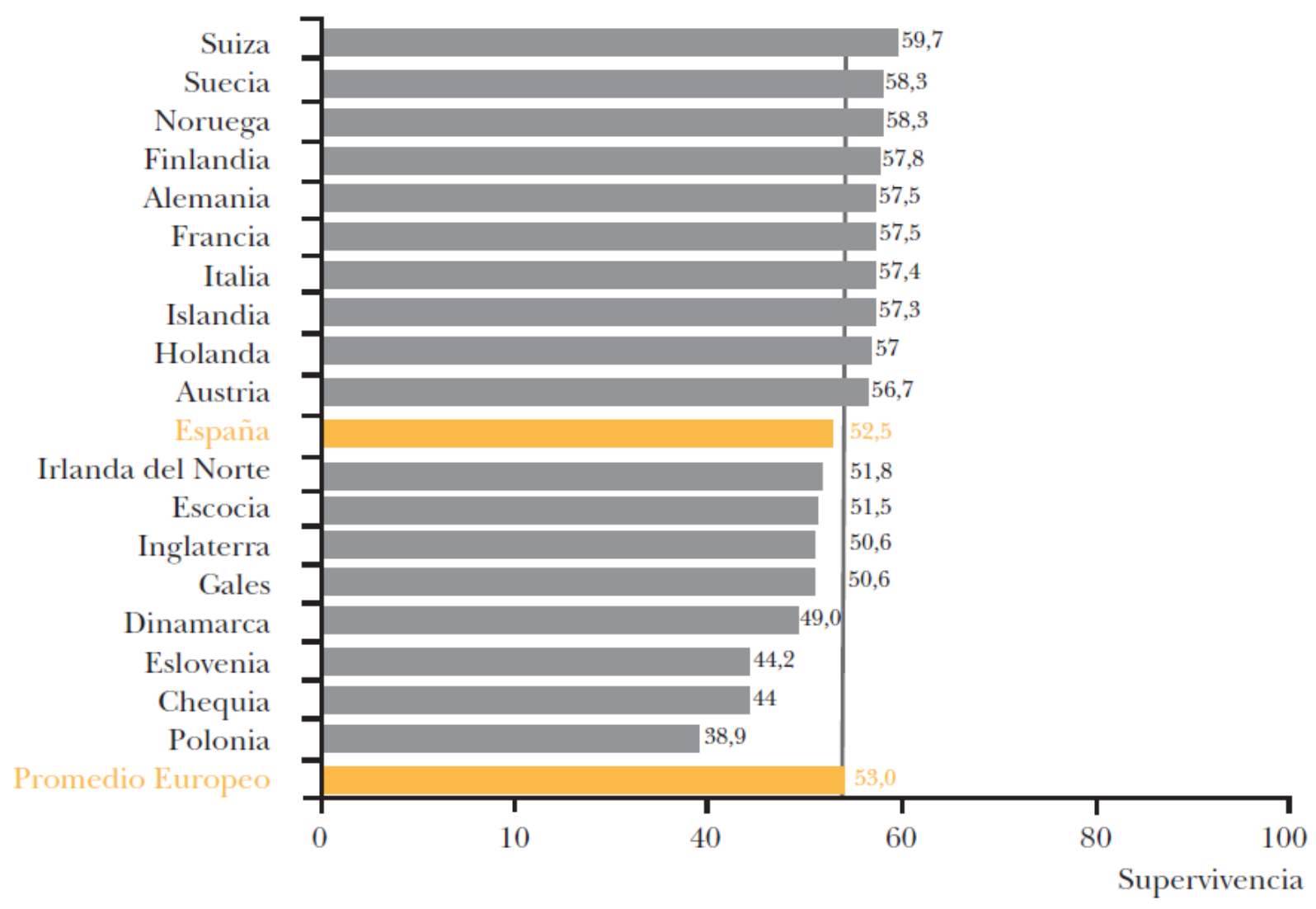

Berrino et al (26).

La supervivencia media del CCR en nuestro país es tan solo del $50 \%$ a los 5 años del diagnóstico ${ }^{2}$, debido posiblemente a que el diagnóstico se realiza de forma tardía en la mayoría de casos.

La supervivencia del CCR depende fundamentalmente del estadio tumoral en el momento del diagnóstico. 


\section{Estadiaje TNM}

American Joint Committee on Cancer (AJCC) TNM Staging System for Colorectal Cancer*

\section{Primary Tumor $(\mathrm{T})$}

TX Primary tumor cannot be assessed

T0 No evidence of primary tumor

Tis Carcinoma in situ: intraepithelial or invasion of lamina propria ${ }^{\dagger}$

T1 Tumor invades submucosa

T2 Tumor invades muscularis propria

T3 Tumor invades through the muscularis propria into the subserosa, or into non-peritonealized pericolic or perirectal tissues

T4 Tumor directly invades other organs or structures, and/or perforates visceral peritoneum ${ }^{\ddagger}$

\section{Regional Lymph Nodes $(\mathrm{N})^{\S}$}

NX Regional lymph nodes cannot be assessed

NO No regional lymph node metastasis

N1 Metastasis in 1 to 3 regional lymph nodes

N2 Metastasis in 4 or more regional lymph nodes

Distant Metastasis (M)

MX Distant metastasis cannot be assessed

MO No distant metastasis

M1 Distant metastasis

\section{Stage Grouping}

\begin{tabular}{lccccc} 
Stage & T & N & M & Dukes & MAC \\
\hline 0 & Tis & N0 & M0 & - & - \\
I & T1 & N0 & M0 & A & A \\
& T2 & N0 & M0 & A & B1 \\
IIA & T3 & N0 & M0 & B & B2 \\
IIB & T4 & N0 & M0 & B & B3 \\
IIIA & T1-T2 & N1 & M0 & C & C1 \\
IIIB & T3-T4 & N1 & M0 & C & C2/C3 \\
IIIC & Any T & N2 & M0 & C & C1/C2/C3 \\
IV & Any T & Any N & M1 & - & D
\end{tabular}

Supervivencia a los 5 años según TNM:

Estadío I..........95-100\%

Estadío II........ 70-85\%

Estadío III....... 50-70\%

Estadío IV ....... 5-15\% 


\section{CRIBADO EN EL CCR FAMILIAR}

Para la estratificación del riesgo de CCR, es fundamental una correcta historia clínica que recoja los antecedentes familiares de adenomas y CCR (se consideran familiares de primer grado a padres, hermanos e hijos, segundo grado a abuelos, tíos y sobrinos, y tercer grado a bisabuelos y primos).

Se considera población de riesgo medio de CCR a los individuos de edad igual o superior a 50 años, sin otros factores de riesgo añadidos; y población de alto riesgo los síndromes hereditarios de CCR, individuos con familiares de primer grado afectos de CCR o pacientes con enfermedad inflamatoria intestinal ${ }^{3-12}$.

Los pacientes de riesgo medio suponen un $70-75 \%$ de los casos de CCR, mientras que en el $20-25 \%$ presentan historia familiar u otro factor de riesgo adicional.

El cribado de CCR en personas asintomáticas que tienen un riesgo medio puede detectar CCR en un estadio precoz, conllevando una mejoría en el pronóstico y por tanto un descenso en la mortalidad. Además, algunas pruebas utilizadas para el cribado de CCR pueden detectar lesiones precursoras de cáncer, produciendo por tanto por tanto una disminución en aparición de nuevos casos.

Estudios prospectivos han mostrado que el cribado endoscópico reduce la incidencia y la mortalidad de CCR en individuos con historia familiar de CCR, por lo que las guías clínicas basadas en la evidencia científica recomiendan el cribado para todos los pacientes con riesgo medio y alto.

El riesgo depende del número de familiares afectos, el grado de parentesco, la edad al diagnóstico y la localización tumoral.

Así, los familiares de primer grado con CCR, sobretodo aquellos casos donde el probando padece CCR a una edad inferior a 60 años, presentan un riesgo acumulado de 2-4 veces superior dependiendo del número y grado de consanguinidad de los familiares afectos. 
Riesgo de CCR en función de la historia familiar: resumen de dos metaanálisis.

Variables

Butterworth*

Baglietto*

Un familiar de primer grado afectado de CCR

Uno o más familiares de primer grado afectados de CCR

Uno o más progenitores afectados de CCR

Uno o más hermanos afectados de CCR

Dos o más familiares de primer grado afectados de CCR

$1,85(1,54-2,22)$

$2,24(2,06-2,43)$

$2,07(1,83-2,34)$

$2,79(2,36-3,29)$

$3,97(2,60-6,06)$

$8,52(5,85-12,41)$

Uno o más familiares de segundo grado afectados de CCR

Individuo de 40 años y uno o más familiares afectados de CCR

Individuo de 50 años y uno o más familiares afectados de CCR

Individuo de 60 años y uno o más familiares afectados de CCR

Individuo de 70 años y uno o más familiares afectados de CCR
$1,73(1,02-2,94)$

$\begin{array}{ll}- & 3,73(2,71-5,14) \\ - & 2,81(2,16-3,66) \\ - & 2,11(1,64-2,71) \\ - & 1,59(1,20-2,10)\end{array}$

$2,03(1,66-2,49)$

$2,26(1,86-2,73)$

$2,15(1,74-2,65)$

$2,52(2,01-3,15)$

$3,95(2,49-6,26)$

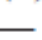

-

$73(2,71-5,14)$

$2,11(1,64-2,71)$

$1,59(1,20-2,10)$

Butterworth et al (24); Baglietto et al (25)

Como se puede observar en la tabla, el riesgo relativo de CCR en individuos con 1 ó más familiares de primer grado afectos de CCR es de 2 aproximadamente; este valor se duplica cuando hay 2 ó más familiares de primer grado afectos.

Se observa también que el riesgo de tener un hermano afecto es superior al de tener un progenitor afecto, aunque sin alcanzar la significación estadística.

El riesgo de CCR en familiares de primer grado de CCR decrece con la edad.

No se han observado diferencias en cuanto al sexo.

Riesgo acumulado de CCR en función de la edad y tras un seguimiento de 10 y 20 años:

$\begin{array}{ccc}\begin{array}{c}\text { Población } \\ \text { general }\end{array} & \begin{array}{c}\text { Un familiar } \\ \text { de primer grado }\end{array} & \begin{array}{c}\text { Dos familiares } \\ \text { de primer grado }\end{array}\end{array}$

\begin{tabular}{|c|c|c|c|}
\hline \multicolumn{4}{|l|}{ En los próximos 10 años: } \\
\hline Individuo de 40 años de edad & $<1 \%$ & $<1 \%$ & $<1 \%$ \\
\hline Individuo de 50 años de edad & $<1 \%$ & $1 \%$ & $2 \%$ \\
\hline Individuo de 60 años de edad & $1,5 \%$ & $2 \%$ & $4,3 \%$ \\
\hline Individuo de 70 años de edad & $2 \%$ & $4 \%$ & $8,3 \%$ \\
\hline \multicolumn{4}{|l|}{ En los próximos 20 años: } \\
\hline Individuo de 40 años de edad & $<1 \%$ & $1 \%$ & $3 \%$ \\
\hline Individuo de 50 años de edad & $2 \%$ & $3 \%$ & $7 \%$ \\
\hline Individuo de 60 años de edad & $3 \%$ & $6 \%$ & $12 \%$ \\
\hline
\end{tabular}


Las guías clínicas basadas en la evidencia científica recomiendan que en individuos con historia familiar de CCR se realice colonoscopia a partir de los 40 años de edad, ó 10 años antes del diagnóstico del familiar afecto más joven; con una periodicidad de 5 años.

\section{PRUEBAS DE CRIBADO}

Si bien en el cribado de las poblaciones de riesgo intermedio se desconoce cuál de los métodos de cribado (detección de sangre oculta en heces (SOH) anual o bienal, sigmoidoscopia cada 5 años, colonoscopia virtual, cápsula de colon o colonoscopia) es el más adecuado, está claramente establecido que en pacientes de alto riesgo (entre ellos los familiares de pacientes con CCR diagnosticados antes de los 60 años), la prueba de elección para el cribado es la colonoscopia ${ }^{6-12}$.

La colonoscopia permite explorar la superficie mucosa de todo el colon. Se considera completa cuando se explora hasta fondo cecal identificando válvula ileocecal u orificio apendicular. Requiere preparación, que consiste en dieta baja en residuos los días previos, junto con limpieza anterógrada con laxantes y agua. Se realiza bajo sedación con fármacos endovenosos.

La colonoscopia es el procedimiento más preciso que existe para la detección precoz y prevención del CCR. Por un lado, estudios observacionales han constatado que la realización de una colonoscopia con polipectomía reduce la incidencia de CCR en un $40-90 \%{ }^{13,14}$; y, por otro lado, la prevalencia de adenomas en estudios transversales de cribado mediante colonoscopia duplica a la observada mediante sigmoidoscopia ${ }^{15-18}$. Se ha visto también que la colonoscopia es más sensible que el enema opaco y la colonoscopia virtual en la detección de pólipos y CCR ${ }^{19}$.

Entre las ventajas adicionales de la colonoscopia se encuentra su efecto protector a largo plazo en el desarrollo de CCR. Ante un examen endoscópico negativo en pacientes de riesgo medio no debe efectuarse repetirse el estudio 
endoscópico hasta pasados 5-10 años, lo que puede influir para mejorar la adherencia de la población. Además, facilita el diagnóstico y el tratamiento en una misma sesión, lo que disminuye el riesgo pérdida de pacientes en el seguimiento como ocurre con otras pruebas que son exclusivamente diagnósticas.

No obstante, una de las principales limitaciones para el uso de la colonoscopia en el cribado de población tanto de riesgo intermedio como alto, es su carácter invasivo, con un eventual riesgo de complicaciones potencialmente graves como la perforación o hemorragia post-polipectomía (12 por cada 1.000 exploraciones). La mortalidad asociada a la colonoscopia es del 0,3 casos por 10.000 exploraciones.

Asimismo, a pesar del uso de sedación en el procedimiento endoscópico, uno de los mayores obstáculos de la colonoscopia es la tolerancia al dolor, hecho que puede conllevar a rechazar futuros seguimientos endoscópicos.

La colonoscopia a veces no es una prueba bien aceptada por los pacientes, debido a la inconveniencia de la prueba, al dolor, y a posible incomodidad. Esto puede limitar la adherencia a la realización de la prueba, teniendo en cuenta que se trata de pacientes asintomáticos.

Asimismo, y a pesar del riesgo incrementado de detección de neoplasias en este grupo de riesgo (familiares de pacientes con CCR diagnosticados antes de los 60 años), una gran mayoría de las exploraciones colonoscópicas serán exploraciones normales.

Por tanto, y teniendo en cuenta lo expuesto previamente (carácter invasivo, tolerancia del dolor durante la exploración endoscópica, riesgo de complicaciones graves y número probable de exploraciones normales), el cribado en pacientes de alto riesgo como es el grupo de pacientes con familiares de primer grado con CCR, que además requiere un inicio precoz de las exploraciones (a los 40 años) y una mayor periodicidad de las exploraciones respecto a la población de riesgo medio (cada 5 años), se podrían beneficiar de técnicas de cribado menos invasivas como la cápsula endoscópica del colon. 


\section{CÁPSULA ENDOSCÓPICA}

La cápsula endoscópica permite una exploración no invasiva de la mucosa colónica. Es un dispositivo que se ingiere fácilmente y que lleva en su interior generadores de imágenes, fuentes de luz, una fuente de energía y un transmisor de radiofrecuencia.

Las ventajas de esta exploración incluyen la eliminación de la necesidad de sedantes, la naturaleza mínimamente invasiva e indolora de la exploración, y la capacidad de continuar con las actividades diarias normales inmediatamente tras el procedimiento (20). Además, comparado con la colonoscopia convencional, la cápsula endoscópica puede ser aceptada más fácilmente por los pacientes, mejorando así su disposición para someterse a una evaluación diagnóstica del colon y cumplir con las recomendaciones del cribado del cáncer colorrectal.

La cápsula PillCam ${ }^{\text {TM }}$ SB que se aprobó por la FDA en Agosto de 2001 para evaluaciones del intestino delgado, ha sido ingerida hasta la fecha por más de 500.000 personas en todo el mundo e igualmente bien aceptada por pacientes, médicos y las diferentes asociaciones profesionales (21). Sin embargo, la visualización adecuada del colon no puede lograrse con la cápsula PillCam ${ }^{\mathrm{TM}}$ SB convencional debido a las propiedades anatómicas y fisiológicas del colon, que son significativamente diferentes a las del intestino delgado. Además, otros problemas que limitan la evaluación de la mucosa del colon por el procedimiento de PillCam ${ }^{\mathrm{TM}} \mathrm{SB}$ convencional, incluyen un nivel insatisfactorio de limpieza del colon y un lento avance de la cápsula de PillCam ${ }^{\mathrm{TM}} \mathrm{SB}$ a través del colon durante el tiempo de exploración deseado.

El Sistema de Diagnóstico Given ${ }^{\circledR}$ está formado por cuatro subsistemas principales: la cápsula, una unidad de grabación de datos, un visualizador en tiempo real y una estación de trabajo RAPID®.

La cápsula PillCam ${ }^{\text {TM }} \mathrm{SB}$ desechable e ingerible, empleada para el estudio del intestino delgado (antiguamente cápsula $M 2 \mathrm{~A}^{\circledR}$ ), adquiere las imágenes de vídeo durante el avance normal a través del sistema digestivo. La cápsula transmite las imágenes adquiridas mediante un canal de comunicación por RF digital a la unidad de grabación ubicada fuera del organismo. La cápsula PillCam ${ }^{\mathrm{TM}}$ SB convencional, con su único formador de imágenes, captura 2 
imágenes por segundo y está bien adecuada para detectar patologías en el intestino delgado. Sin embargo, debido a las propiedades anatómicas y fisiológicas del colon, no puede garantizarse una visualización suficiente a este nivel cuando se usa la cápsula Pill $\mathrm{Cam}^{\mathrm{TM}} \mathrm{SB}$ convencional.

La cápsula PillCam ${ }^{\mathrm{TM}}$ Colon (PCCE) que se utiliza en este estudio, posee una óptica mejorada con un campo de visión más amplio (125 grados) y más profundo $(40 \mathrm{~mm})$. Presenta otras ventajas con respecto a la cápsula PillCam ${ }^{\mathrm{TM}}$ SB convencional:

- La cápsula de colon tiene 2 generadores de imágenes que permiten a la cápsula adquirir imágenes de vídeo desde ambos extremos de la cápsula.

- Diámetro similar al de la PillCam ${ }^{\mathrm{TM}} \mathrm{SB}$ pero es ligeramente más larga; aproximadamente $5 \mathrm{~mm}$ más larga que la cápsula de intestino delgado $(26,4 \mathrm{~mm})$.

- Frecuencia de imagen superior (4 imágenes por segundo) y puede dejar de funcionar de una manera programada y durante un tiempo determinado con el fin de ahorrar energía hasta que alcanza el colon.

La envoltura de la cápsula de colon está fabricada con materiales biocompatibles.

Se han realizado diversos ensayos clínicos con la cápsula de PillCam ${ }^{\mathrm{TM}}$ Colon y se ha establecido la seguridad de la misma ${ }^{22}$.

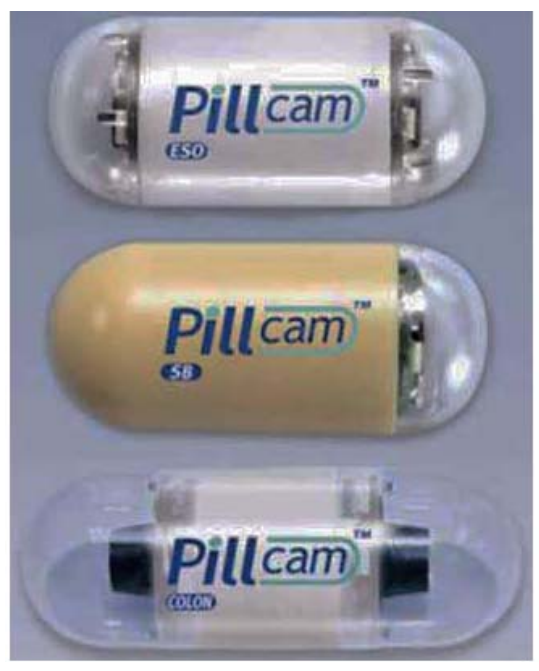


El primer estudio multicéntrico, prospectivo y comparativo en la evaluación de la cápsula endoscópica para el estudio de patología colónica fue publicado por Eliakim y colaboradores en $2006^{21}$, en el que se incluyeron 91 pacientes a los que se les realizó colonoscopia y cápsula endoscópica; la indicación de colonoscopia era sospecha de patología del colon ó cribado de CCR. La tasa de excreción dentro de las primeras horas fue del 78\%. La sensibilidad (S) y especificidad (E) para la detección de pólipos mayores de 6 mm ó al menos 3 pólipos de cualquier tamaño, fue de 50\% y 83\%, respectivamente, con unos valores predictivos positivos (VPP) y negativos (VPN) de $40 \%$ y $88 \%$ respectivamente.

Otro estudio similar fue publicado por Schoofs y colaboradores en 2006 22. Incluyeron 41 pacientes pudiendo analizar únicamente 37 de ellos; la indicación era sospecha de patología de colon o cribado de cáncer; objetivaron una tasa de excreción dentro de las primeras 10 horas del $84 \%$, en el $68 \%$ de los pacientes se objetivó algún pólipo. La $\mathrm{S}$ y $\mathrm{E}$ para detección de pólipos mayores de $6 \mathrm{~mm}$ ó al menos 3 pólipos fue de 77\% y 71\% respectivamente, con VPP de 59\% y VPN de $84 \%$.

Posteriormente Lewis et al realizaron otro estudio $(n=51)$ comparando la cápsula de colon junto con la colonografía por TC y la colonoscopia, utilizando como método de referencia la colonoscopia. La sensibilidad de la cápsula para la detección de pólipos de cualquier tamaño fue de $79 \%$, la E fue de $53 \%$ y los valores predictivos positivo y negativo fueron de $50 \%$ y $81 \%$.

A finales del año pasado se publicó en New England Journal of Medicine un estudio multicéntrico europeo realizado de forma prospectiva, que comparaba la cápsula endoscópica de colon con la colonoscopia en la detección de pólipos y cáncer. Se incluyeron 328 pacientes. Los resultados fueron los siguientes: la sensibilidad y especificidad de la cápsula endoscópica para la detección de pólipos mayores de $6 \mathrm{~mm}$ fue de 64\% y 84\%; para adenomas avanzados fue de $73 \%$ y $79 \%$ y para cáncer tuvo una sensibilidad del 74\%. Para todas las lesiones, la sensibilidad de la cápsula endoscópica mejoraba en pacientes con nivel de limpieza bueno o excelente. Los autores 
concluían que a pesar de que la cápsula permite la visualización mucosa en la mayoría de pacientes, la sensibilidad para detectar lesiones colónicas es baja con respecto a la colonoscopia.

En el pasado congreso Europeo (Sacher-Huvelin et al, Londres UEGW, Noviembre 2009) se presentaron los resultados de un estudio multicéntrico francés, entre los que se incluían pacientes de riesgo medio y alto de presentar CCR. Se incluyeron 502 pacientes pero en el congreso se presentaron los resultados de 105 pacientes. Se les realizó cápsula de colon y colonoscopia (utilizada como método de referencia). La prevalencia de pólipos mayores de 6 $\mathrm{mm}$ detectados por cápsula y colonoscopia fue de $22 \%$ y $21 \%$ respectivamente, la sensibilidad fue de $55 \%$, especificidad de $87 \%$, con VPP de $52 \%$ y VPN de $88 \%$. Los resultados en pacientes con limpieza buena 0 excelente fueron: S 69\%, E 84\%, VPP 56\% y VPN 90\%.

En la reunión de Digestive Disease Week este año (Eliakim et al, AGA, New Orleans, Mayo 2010), presentó un avance de los resultados de la nueva generación de cápsula endoscópica colónica, con mejoría respecto a los publicados en estudios previos.

Existe, pendiente de publicar, un meta-análisis (Spada et al. Clinical Gastroenterology and Hepatology. En prensa) en el que se analizan 837 pacientes incluidos en 8 estudios que comparan la cápsula endoscópica respecto a la colonoscopia. La sensibilidad de la cápsula endoscópica en detectar pólipos y lesiones significativas fue de $71 \%$ y $68 \%$ respectivamente, y la especificidad fue de $75 \%$ y $82 \%$ respectivamente. En la discusión los autores argumentan que probablemente la especificidad de la cápsula en la detección de pólipos está infraestimada debido a que se realice de forma ciega para los resultados de la colonoscopia en todos los estudios. 


\begin{tabular}{|c|c|c|c|c|c|c|c|c|c|c|c|}
\hline Author & $\begin{array}{c}\text { Year of } \\
\text { Publication }\end{array}$ & $\begin{array}{l}\text { Study } \\
\text { Country }\end{array}$ & $\begin{array}{c}\text { Full } \\
\text { paper/abstract }\end{array}$ & Centres & $\begin{array}{c}\mathrm{N}^{\circ} \\
\text { Patients }\end{array}$ & $\begin{array}{c}\text { Male sex } \\
\quad \%\end{array}$ & $\begin{array}{l}\text { Mean age } \\
\text { Years }\end{array}$ & $\begin{array}{l}\mathrm{N}^{\circ}(\%) \\
\text { Patients } \\
\text { included }\end{array}$ & $\begin{array}{c}\mathrm{N}^{\circ}(\%) \\
\text { Patients } \\
\text { asymptomatic }\end{array}$ & $\begin{array}{c}\mathrm{N}^{\circ}(\%) \\
\text { Patients with good-excellent } \\
\text { bowel preparation }\end{array}$ & $\begin{array}{c}\mathrm{N}^{\circ}(\%) \\
\text { Patients with } \\
\text { CCE excretion }\end{array}$ \\
\hline Eliakim et al. ${ }^{s}$ & 2006 & Israel & Full paper & Multicentric & 91 & $60 \%$ & 57 & $84(92)$ & $58(69)$ & $38(84)$ & $67(80)$ \\
\hline Schoofs et $a L^{6}$ & 2006 & Belgium & Full paper & Monocentric & 41 & $37 \%$ & 56 & $36(88)$ & $17(41)$ & $31(89)$ & $30(83)$ \\
\hline Van Gossum et al. ${ }^{7}$ & 2009 & Europe & Full paper & Multicentric & 332 & $55 \%$ & 58 & $320(96)$ & $0(0)$ & $230(72)$ & $302(94)$ \\
\hline Sieg et al. ${ }^{8}$ & 2009 & Germany & Full paper & Monocentric & 38 & $83 \%$ & 56 & $36(95)$ & $36(100)$ & $28(88)$ & $27(75)$ \\
\hline Spada et al. ${ }^{15}$ & 2008 & Italy & Abstract & Monocentric & 40 & $42 \%$ & 58 & $40(100)$ & $18(45 \%)$ & $17(42)$ & $35(88)$ \\
\hline Gay et al. ${ }^{16}$ & 2009 & France & Full paper & Monocentric & 128 & $52 \%$ & 55 & $126(98)$ & $74(58)$ & $103(82)$ & $114(90)$ \\
\hline Sacher-Huvelin et al. ${ }^{17}$ & 2009 & France & Abstract & Multicentric & 105 & $63 \%$ & 60 & $105(100)$ & $105(100)$ & $58(55)$ & $\mathrm{NA}^{5}$ \\
\hline Pilz et al. ${ }^{18}$ & 2008 & Switzerland & Abstract & Monocentric & 62 & $59 \%$ & 59 & $59(95)$ & $30(54)$ & $15(27)$ & $36(88)$ \\
\hline
\end{tabular}

Spada et al, en prensa

\section{OBJETIVOS}

En este estudio proponemos estudiar la capacidad diagnóstica de la cápsula endoscópica en el screening del $\mathrm{CCR}$, en una población de riesgo medio (pacientes con antecedentes familiares de CCR), en comparación con la colonoscopia, que se utiliza como método de referencia.

Se propone además la utilización de un régimen modificado de preparación intestinal para la realización de la cápsula de colon que nos permitirá evaluar de manera prospectiva el nivel de limpieza colónico (score de limpieza colónica - Anexo 1), su influencia en la capacidad diagnóstica de la técnica y la tasa de excreción de cápsulas o estudios completos.

\section{Objetivos primarios}

- Detección de neoplasias (adenomas avanzados o cáncer)

- Evaluar el efecto de la preparación con Moviprep en la limpieza colónica.

\section{Objetivos secundarios}

- Detección de adenomas no avanzados

- Valoración del grado satisfacción del método cribado

- Evaluar el efecto de la preparación colónica en el tiempo de tránsito.

- Evaluar la seguridad del procedimiento con cápsula endoscópica colónica.

- Evaluar la tasa de excreción de cápsulas en 10 horas 


\section{MATERIAL Y MÉTODOS}

Se trata de un estudio piloto, prospectivo y unicéntrico.

Los pacientes realizaron una exhaustiva limpieza colónica con Moviprep, que se explica en el esquema a continuación. El día previo a la exploración se permitió a los pacientes ingesta de pasta alimenticia en dos dosis para asegurar de esta manera una adecuada motilidad intestinal.

Todos los pacientes firmaron un consentimiento informado.

Se realizaron ambas pruebas en el mismo día, la cápsula a primera hora de la mañana, y la colonoscopia aproximadamente 8 horas después.

\section{Esquema preparación}

\begin{tabular}{|l|l|}
\hline DÍA -1 & Dieta líquida \\
\hline & $12 \mathrm{~h}$. Comida: $200 \mathrm{~g}$ fideos + agua \\
\hline & $17 \mathrm{~h}$. Comida: $200 \mathrm{~g}$ fideos + agua \\
\hline DIA 0 & 19-21: 1 litro moviprep + 1 litro agua \\
\hline & $7 \mathrm{~h}$ : 1 litro moviprep+ 1 litro agua \\
\hline & $9 \mathrm{~h}: 10 \mathrm{mg}$ metoclopramida \\
\hline & $9: 30 \mathrm{~h}$. CÁPSULA \\
\hline & $\begin{array}{l}1^{\circ} \text { boost- } 2 / 3 \text { I. Moviprep + agua en } 30 \\
\text { min (tras pasar píloro) }\end{array}$ \\
\hline & $\begin{array}{l}2^{\circ} \text { boost- } 1 / 3 \text { I. Moviprep + agua en } 15 \\
\text { min (3 horas tras el } 1^{\circ} \text { boost) }\end{array}$ \\
\hline & $\begin{array}{l}\text { Tras } 5 \text { horas: supositorio (si no se ha } \\
\text { expulsado ya la cápsula) }\end{array}$ \\
\hline COLONOSCOPIA \\
\hline
\end{tabular}




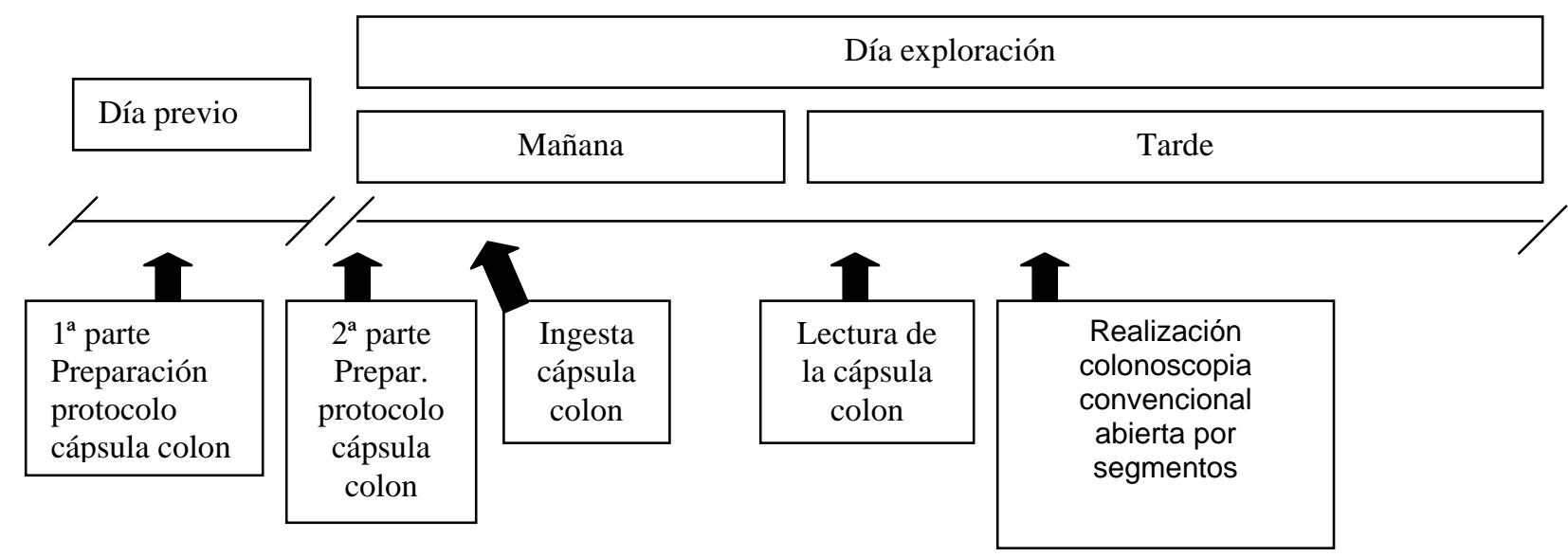

Todos los vídeos RAPID de cápsula endoscópica generados se revisaron por un médico con experiencia y formación. Los médicos que realizaron las lecturas tenían experiencia previa con PillCam SB y cápsula de colon, además de haberse sometido a una formación normalizada con el fin de interpretar vídeos de cápsula de colon.

Tras el procedimiento de cápsula, se realizó una colonoscopia convencional por un especialista en colonoscopias, ciego para los resultados de la cápsula. Los resultados de cápsula se compararon con los del procedimiento de colonoscopia tradicional. Asimismo se recogieron otros datos como la limpieza, los efectos secundarios de las exploraciones realizadas y el grado de satisfacción para cada una de ellas.

Para evaluar el grado de satisfacción de cada prueba se elaboró un cuestionario de satisfacción consistente en 10 preguntas. Hasta la fecha no ha sido completado por todos los pacientes por lo que no se ha incluido en este análisis.

\section{Población a estudio}

- Pacientes con al menos un familiar de primer grado diagnosticado de cáncer colorrectal antes de los 60 años de edad 
- Pacientes con dos o más familiares, de primer o segundo grado, diagnosticados de cáncer colorrectal independientemente de la edad del diagnóstico

\section{Criterios de inclusión}

- Edad superior a 40 años o 10 años antes de la edad de diagnóstico del familiar afecto más joven

- Obtención consentimiento informado

\section{Criterios de exclusión}

- Historia previa de adenomas y/o cáncer colorrectal

- Antecedente de enfermedad inflamatoria intestinal, síndromes polipósicos del colon o cáncer colorrectal hereditario no poliposis

- Historia previa de disfagia o cualquier trastorno deglutorio.

- Insuficiencia cardiaca congestiva.

- Alto grado de insuficiencia renal.

- Cirugía abdominal anterior del tracto gastrointestinal distinta a procedimientos sin complicación que es improbable que condujeran a la obstrucción del intestino basándose en el criterio clínico del investigador. - Alergia u otra contraindicación conocida a la preparación usada en el estudio.

- Riesgo aumentado de retención de la cápsula tal como enfermedad de Crohn, tumores intestinales, enteritis por radiación, o enteropatía por AINE.

- Mujeres que o bien están embarazadas o en periodo de lactancia en el momento de la selección.

El estudio ha respetado los principios fundamentales establecidos en la Declaración de Helsinki, en el Convenio del Consejo de Europa relativo a los Derechos Humanos y la Biomedicina, en la Declaración Universal de la UNESCO sobre el genoma humano y los derechos humanos, así como cumplirá los requisitos establecidos en la legislación española en el ámbito de la investigación biomédica, la protección de datos de carácter personal y la bioética. 


\section{RESULTADOS}

\section{Características generales de los pacientes}

Se incluyeron un total de 30 pacientes. Un paciente fue excluido del análisis final por abandonar el estudio antes de finalizar. Las características epidemiológicas se resumen en la tabla 1: La proporción entre sexos fue similar. La edad media de los pacientes fue de 47,9 años. Un $13,8 \%$ de los pacientes tenían antecedente de cirugía abdominal previa, y un 10,3\% estaba bajo tratamiento con antiinflamatorios ó antiagregación, mientras que no hubo ningún paciente en tratamiento anticoagulante.

\section{Tabla 1. Características basales de los pacientes}

\begin{tabular}{|ll|}
\hline Sexo (H/M) & $13 / 16$ \\
Edad media (años) & $47.9 \pm 9,01$ \\
& \\
Cirugía previa (\%) & 13,8 \\
Uso de AINES (\%) & 6,9 \\
Antiagregantes (\%) & 3,4 \\
Anticoagulación (\%) & 0 \\
\hline
\end{tabular}

Todos los pacientes incluidos tenían un familiar de primer grado diagnosticado de CCR antes de los 60 años de edad, o dos o más familiares de primer o segundo grado, independientemente de la edad.

El número medio de familiares con CCR fue de 1,24. Un 93,3\% de los pacientes tenían al menos un familiar de primer grado diagnosticado de CCR, con una media de edad al diagnóstico de 58,4 años. El 17,4\% de los pacientes tenían dos familiares o más diagnosticados de CCR (tabla 2). 
Tabla 2.

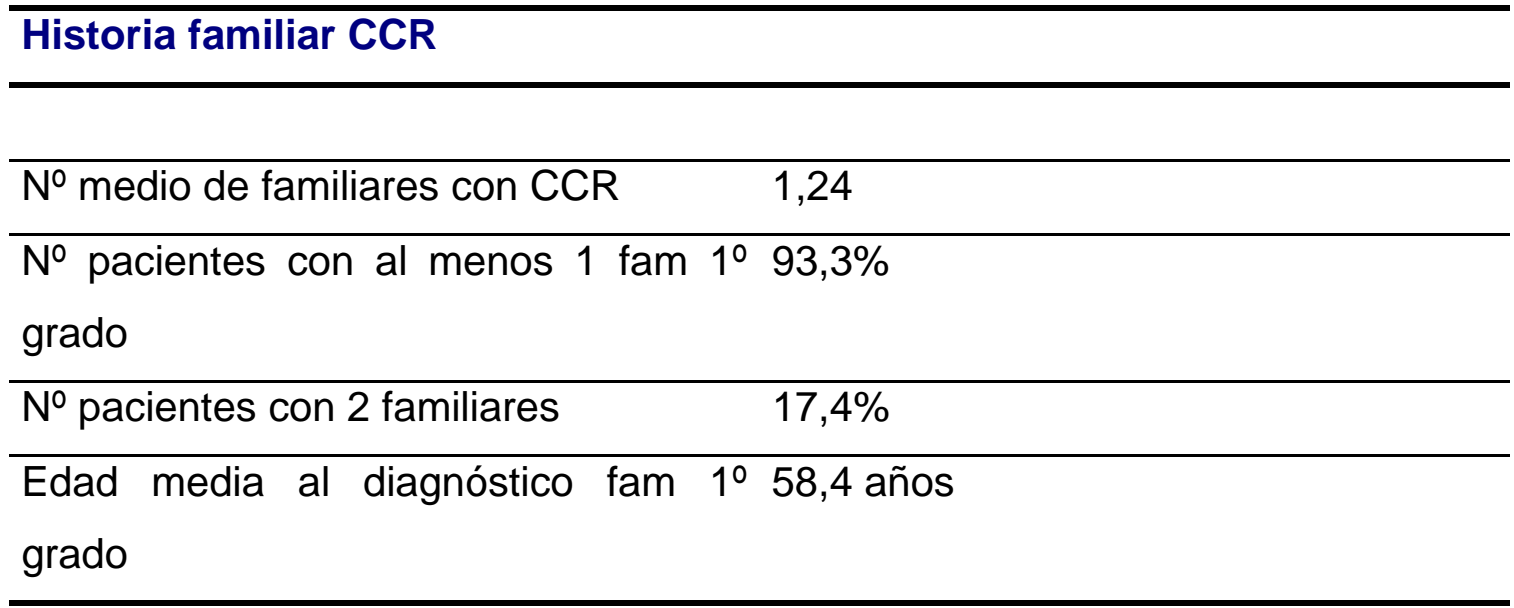

\section{Cápsula endoscópica colónica}

En 4 casos se realizó previamente Cápsula Patency para la comprobación de una correcta permeabilidad intestinal. Los motivos fueron cirugía abdominal previa en un caso y uso de AINES y/o antiagregantes en tres casos. En todos ellos se expulsó intacta la cápsula Patency.

No hubo problemas con la deglución de la cápsula endoscópica, excepto en un paciente que presentó dificultad para el paso, pero que finalmente consiguió deglutirla.

En todos los casos se comprobó paso gástrico a través del visualizador en tiempo real.

\section{Colonoscopia}

Las colonoscopias se llevaron a cabo por un endoscopista ciego para el resultado de la cápsula endoscópica.

Todas las colonoscopias se realizaron bajo sedación, la medicación utilizada varió según el criterio del endoscopista, realizándose en 22 pacientes con midazolam y fentanilo $(75,8 \%)$ y en 7 pacientes con propofol $(24,1 \%)$.

La colonoscopia fue completa en 28 de los 29 pacientes, en un caso no se consiguió llegar a fondo cecal por dificultad técnica. 


\section{Limpieza del colon}

La limpieza del colon se evaluó según un score de limpieza colónica utilizado de forma similar en estudios previos (anexo 1).

Como se puede observar en la tabla, de forma global se alcanzó un grado de limpieza bueno o excelente en el $65,5 \%$ de los casos mediante cápsula endoscópica y en el 89,7\% mediante colonoscopia, datos que ascienden a 79,3 y $100 \%$ si se incluye también el grado de limpieza aceptable.

Quedan por tanto un 20,7 \% de pacientes con preparación inadecuada en la cápsula endoscópica.

No hubo diferencias en cuanto a la preparación al analizar la limpieza por segmentos del colon, aunque sí una tendencia a la mejoría en el grado de limpieza en los tramos distales del colon.

EXCELENTE/BUENO

\begin{tabular}{|l|l|l|l|l|}
\hline & $\begin{array}{l}\text { Cápsula } \\
\%\end{array}$ & $\begin{array}{l}\text { Colonoscopia } \\
\%\end{array}$ & $\begin{array}{l}\text { Cápsula } \\
\text { Bueno/ } \\
\text { Excelente/ } \\
\text { Aceptable } \\
\%\end{array}$ & $\begin{array}{l}\text { Colonoscopia } \\
\text { Bueno/ } \\
\text { Excelente/ } \\
\text { Aceptable } \\
\%\end{array}$ \\
\hline Global & 65,5 & 89,7 & 79,3 & 100 \\
\hline Ciego & 62 & 89,6 & 72,3 & 100 \\
\hline Ascendente & 62,1 & 86,2 & 79,3 & 100 \\
\hline Transverso & 69 & 86,2 & 79,3 & 100 \\
\hline Descendente & 72,4 & 89,6 & 82,7 & 100 \\
\hline Rectosigma & 69 & 89,3 & 89,7 & 100 \\
\hline
\end{tabular}




\section{Tasa de excreción dentro de las primeras 10 horas}

En el $79 \%$ de los casos la cápsula de expulsó de forma espontánea antes de las $10 \mathrm{~h}$ tras la ingesta de ésta.

En 6 pacientes $(20,7 \%)$ se realizó extracción endoscópica durante la colonoscopia debido a que la cápsula todavía no se había expulsado, aunque no se hubiesen cumplido las 10 horas tras la ingesta.

De éstos 6 casos, la cápsula estaba en el recto en 2 pacientes, objetivándose paquete hemorroidal, por lo que si consideramos que ésta se hubiese expulsado de forma espontánea, la tasa de excreción dentro de las primeras 10 h sería de 86,2\%. De los 4 pacientes restantes, en 3 pacientes la cápsula se encontraba en el sigma, y en un paciente estaba todavía en fondo cecal.

\section{Hallazgos endoscópicos}

La prevalencia de pólipos mediante cápsula endoscópica y colonoscopia fue del $20,7 \%$ y del $24,1 \%$ respectivamente.

El número total de pólipos de cualquier tamaño detectados por cápsula fue de 18, y por colonoscopia de 19.

En la tabla 3 se resumen los pacientes con pólipos detectados por alguna de las dos pruebas.

Tabla 3. Resumen de pacientes con pólipos

\begin{tabular}{|l|l|l|}
\hline & Cápsula & Colonoscopia \\
\hline 1 & 1 p. Recto, $3 \mathrm{~mm}$ & $1 \mathrm{p}$. Recto, $4 \mathrm{~mm}$ \\
\hline 2 & 1 p. Sigma, $2 \mathrm{~mm}$ & $3 \mathrm{p} 5,2$ y $2 \mathrm{~mm}$. \\
\hline 3 & $2 \mathrm{p} .5 \mathrm{~mm}$ y $2 \mathrm{~mm}$ & 0 \\
\hline 4 & 7 p. $(7 \mathrm{~mm}$, el resto $2-3 \mathrm{~mm})$ & $7 \mathrm{p}$ (todos $<6 \mathrm{~mm})$ \\
\hline 5 & 1 p. Sigma $10 \mathrm{~mm}$ & 1 p. Sigma $10 \mathrm{~mm}$ \\
\hline 6 & $6 \mathrm{p}(3>6 \mathrm{~mm}, 3<6 \mathrm{~mm})$ & $5 \mathrm{p} \rightarrow 6 \mathrm{p} *(3>6 \mathrm{~mm})$ \\
\hline 7 & $0 \mathrm{p}$. & $1 \mathrm{p}$. Sigma, $3 \mathrm{~mm}$ \\
\hline 8 & $0 \mathrm{p}$. & $1 \mathrm{p}$. Sigma $3 \mathrm{~mm}$. \\
\hline Total pólipos & 18 & 20 \\
\hline
\end{tabular}

*tras $2^{\mathrm{a}}$ colonoscopia 
La sensibilidad y especificidad de la cápsula endoscópica para la detección de pólipos de cualquier tamaño sería de 71\% y 95,4\%, respectivamente, con VPP de $83,3 \%$ y VPN de $91,3 \%$.

La sensibilidad y especificidad de la cápsula endoscópica para la detección de pólipos mayores de $6 \mathrm{~mm}$ fue de 100\% y 100\%, respectivamente, con VPP de $100 \%$ y VPN de $100 \%$

Pólipos de cualquier tamaño

Recuento

\begin{tabular}{|ll|r|r|r|}
\hline \multirow{2}{*}{} & \multicolumn{2}{|c|}{ Pólipo CE global } & \multirow{2}{*}{} \\
\cline { 3 - 5 } & & no & si & Total \\
\hline Presencia de pólipos en & No & 21 & 1 & 22 \\
EDB & Si & 2 & 5 & 7 \\
Total & & 23 & 6 & 29 \\
\hline
\end{tabular}

Pólipos > $6 \mathrm{~mm}$

Recuento

\begin{tabular}{|c|c|c|c|c|}
\hline & \multicolumn{2}{|c|}{$\begin{array}{c}\text { Algún pólipo detectado por CE } \\
\text { mayor de } 6 \mathrm{~mm}\end{array}$} & \multirow[b]{2}{*}{ Total } \\
\hline & & no & si & \\
\hline Algún pólipo detectado por & No & 26 & 0 & 26 \\
\hline $\begin{array}{l}\text { colonoscopia mayor de } 6 \\
\mathrm{~mm}\end{array}$ & $\mathrm{Si}$ & 0 & 3 & 3 \\
\hline Total & & 26 & 3 & 29 \\
\hline
\end{tabular}

Hubo dos casos de detección de pólipos por cápsula endoscópica que no se detectaron mediante colonoscopia: en un caso se trataba de un pólipo mayor de $6 \mathrm{~mm}$, se repitió la colonoscopia y se detectó el pólipo en la localización correspondiente, por lo que no se ha contado como falso positivo, y dicho pólipo se ha añadido al total de pólipos detectados por colonoscopia, en total 20. En el otro caso, se detectaron dos pólipos ambos menores de $6 \mathrm{~mm}$, y en el momento actual se encuentra pendiente de repetir la colonoscopia, por lo que para el análisis se han contado como falsos positivos de la cápsula endoscópica. 
En los casos en que se no se objetivaron pólipos por cápsula y sí por colonoscopia (2 pacientes, cada paciente con un pólipo menor de $6 \mathrm{~mm}$ ) se realizó segunda lectura de la cápsula, sin objetivar nuevos hallazgos en ninguno de los dos casos.

Si analizamos los casos con mala preparación de forma global en la cápsula endoscópica $(n=5)$ y comparamos los hallazgos endoscópicos en ambas técnicas, observamos que no hubo diferencias en cuanto a los hallazgos endoscópicos.

Respecto a la histología de los pólipos resecados, fueron en un 60\% adenomas tubulares, en un 20\% adenomas tubulo-vellosos y en el 20\% restante pólipos hiperplásicos.

No se diagnosticó ningún caso de CCR.

\section{Efectos adversos}

No hubo efectos adversos importantes con la cápsula endoscópica, pero sí tres casos de problemas técnicos por batería insuficiente. En uno de los casos se le administró una segunda cápsula con correcta visualización posterior. En los otros dos casos la exploración fue incompleta, pero no tradujo diferencias en cuanto a los hallazgos endoscópicos.

\section{Grado de satisfacción del método}

El grado de satisfacción de cada método no se ha podido analizar dado que todavía no se han completado todos los cuestionarios por parte de los pacientes. 


\section{DISCUSIÓN}

La cápsula de colon representa una novedosa técnica no invasiva e indolora, que permite explorar el colon sin necesidad de sedación o insuflación. En los últimos años la evidencia ha demostrado que se trata de una técnica segura y bien tolerada.

El cribado del cáncer colorrectal está cobrando cada vez más importancia y se está implementando en numerosos países. En este sentido, diversos estudios sugieren que la cápsula endoscópica podría tratarse de una alternativa segura y eficaz a la colonoscopia.

El presente estudio, realizado de forma prospectiva, ofrece resultados favorables para la realización de esta técnica. Demuestra una sensibilidad y especificidad de $71,4 \%$ y $95,4 \%$ en la detección de pólipos de cualquier tamaño. Si tenemos en cuenta únicamente los pólipos mayores de $6 \mathrm{~mm}$, se han objetivado tras una segunda colonoscopia en caso de falsos positivos, una $S$ y $E$ del $100 \%$. Estos datos pueden haber sido tan positivos en parte por la experiencia de los endoscopistas, y en parte debido al número pequeño de pacientes, siendo probablemente algo menores si ampliásemos la muestra.

En el contexto del cribado del cáncer colorrectal, aunque mediante cápsula endoscópica puede no objetivarse un pequeño número de pólipos, el hecho de que sea una técnica no invasiva, con mejor aceptabilidad por parte de los pacientes, podría por otra parte suponer una mejor adherencia al cribado.

Si bien es verdad que si se detectan lesiones por cápsula endoscópica, es necesario realizar una colonoscopia para biopsiarlas y extraerlas, también es cierto que la mayoría de pacientes tendrán una exploración sin lesiones patológicas; si a esto añadimos el hecho de que es una población que requiere controles periódicos más estrechos, serían muchas las colonoscopias que se evitarían.

La precisión de la cápsula depende en gran medida del grado de limpieza alcanzado; en este estudio se evalúa también la preparación con Moviprep. Los niveles de limpieza conseguidos son similares a los descritos en estudios previos. Mediante la preparación con Moviprep, el volumen administrado de forma global (unos 4 litros en total) es menor que con la preparación habitual utilizada para la cápsula endoscópica (unos 5 litros en 
total), por tanto, puede suponer una mejor aceptabilidad por parte de los pacientes; en nuestro estudio hemos observado una tolerancia excelente en todos los pacientes, aunque no se ha comparado con otras preparaciones.

No se han producido efectos adversos graves, dato que concuerda con la literatura al respecto y que confirma la seguridad de esta técnica.

La principal limitación de este estudio es el tamaño reducido de la muestra, que se pretende ampliar a corto plazo.

Por otro lado, por el momento no hay estudios que evalúen costeefectividad de esta técnica, aspecto que también es muy importante para la aplicación de una técnica de cribado de cualquier enfermedad.

Podemos decir que la cápsula endoscópica ofrece una alternativa fiable, precisa, bien tolerada y segura a la colonoscopia y podría ser de elección en casos seleccionados, como pacientes con mucha dificultad técnica ó con mala tolerancia a la colonoscopia.

\section{CONCLUSIONES}

- La cápsula endoscopica supone una herramienta precisa, fiable, bien tolerada y segura en el cribado familiar de cáncer colorrectal.

- La preparación con Moviprep permite un grado de limpieza similar, con excelente tolerancia.

- Son necesarios más estudios encaminados a mejorar la preparación colónica y analizar coste efectividad de la técnica. 


\section{ANEXOS}

Anexo 1.- Evaluación de la preparación colónica

Procedimiento:

Colonoscopia

PillCam CE

(cápsula colon)

\begin{tabular}{|c|c|l|}
\hline \multicolumn{2}{|c|}{ Grado de limpieza } & \multicolumn{1}{c|}{ Descripción } \\
\hline Grado 1 & Malo & $\begin{array}{l}\text { Inadecuado: impide una exploración completa (gran cantidad de } \\
\text { residuos fecales) }\end{array}$ \\
\hline Grado 2 & Aceptable & $\begin{array}{l}\text { Inadecuado: exploración completa (bastantes heces o líquido oscuro } \\
\text { presentes como para impedir una exploración fiable) }\end{array}$ \\
\hline Grado 3 & Bueno & $\begin{array}{l}\text { Adecuado con algo de líquido (pequeñas cantidades de heces o líquido } \\
\text { oscuro que no interfieren con la exploración) }\end{array}$ \\
\hline Grado 4 & Excelente & Excelente (sólo pequeños trozos de heces adherentes) \\
\hline
\end{tabular}




\section{BIBLIOGRAFIA}

1. Informe sobre la salud de los españoles - Cáncer. Centro Nacional de Epidemiología. Diciembre 2003.

2. Keighley MRB et al. Gastrointestinal Cancers in Europe. Aliment Pharmacol Ther 2003;18 Suppl 3: 7-30.

3. Screening for colorectal cancer. Report of the U.S. Preventive Services Task Force. Washington DC, 1995.

4. Levin B et al. Screening and surveillance for the early detection of colorectal cancer and adenomatous polyps CA Cancer J Clin 2008 May-Jun; 58(3): 130-60.

5. Young GP et al. Choice of fecal occult blood tests for colorectal cancer screening. Am J Gastroenterol.2002;97:2499-507.

6. Winawer $\mathrm{S}$, et al. Colorectal cancer screening and surveillance: clinical guidelines and rationale-update based on new evidence. Gastroenterology. 2003;124:544-60

7. Smith RA et al, American Cancer Society guidelines for the early detection of cancer. CA Cancer J Clin. 2003;53:27-43.

8. Barkun AN et al. The Quebec Association of Gastroenterology position paper on colorectal cancer. Can J Gastroenterol. 2004;18:509-19.

9. Rex DK et al. American College of Gastroenterology action plan for colorectal cancer prevention. Am J Gastroenterol. 2004;99:574-7.

10. Leddin D, et al. Canadian Association of Gastroenterology and the canadian Digestive Health Foundation. Can J Gastroenterol. 2004;18:93-9. 
11. Improving Outcomes in Colorectal Cancers. National Institute for Clinical Excellence. May 2004.

12. Castells A et al. Clinical guidelines for the Prevention for Colorectal Cancer. Gastroenterol Hepatol 2004;27:573-634.

13. Muller A et al. Prevention of colorectal cancer by flexible endoscopy and polypectomy. A case-control study of 32702 veterans. Ann Intern Med 1995;123: 904-10.

14. Winawer SJ et al. Prevention of colorectal cancer by colonoscopic polypectomy. The National Polyp Study Workgroup. N Engl J Med 1993;329:1977-1981.

15. Rex DK et al. Colonic neoplasia in asymptomatic persons with negative fecal occult blood tests: influence of age, gender and family history. Am J Gastroenterol 1993;88:825-31.

16. Lieberman DA et al. Screening for colon malignancy with colonoscopy. Am J Gastroenterol 1991;86:946-51.

17. Lieberman DA et al. Use of colonoscopy to screen asymptomatic adults for colorectal cancer. Veterans affairs cooperative sutdy group. N Engl J Med 2000;343:162-168.

18. Imperiale TF et al. Risk of advanced proximal neoplasms in asymptomatic adults according to the distal colorectal findings. $N$ Engl $J$ Med 2000;343:169-174.

19. D C Rockey, et al. Analysis of air contrast barium enema, computed tomographic colonography, and colonoscopy: prospective comparison. Lancet 2005; 365: 305-11. 
20. Mishkin et al., ASGE Technology Status Evaluation Report: wireless capsule endoscopy. Gastrointest Endosc 2006; 63: 539-45.

21. Eliakim et al.: Evaluation of PillCam Colon capsule in the detection of colonic pathology. Endoscopy 2006; 38: 963-70

22. Schoofs et al.: PillCam colon capsule endoscopy compared with colonoscopy. Endoscopy 2006; 38: 917-77

23. Butterworth et al. Relative and absolute risk of colorectal cancer for individuals with a family history: a meta-analysis. Eur J Cancer 2006;42: 216-27

24. Baglietto $L$ et al. Measures of familiar aggregation depend on definition of family history: a meta-analysis for colorrectal cancer. J Clin Epidemiol 2006; 59: 114-124.

25. Berrino $\mathrm{F}$ et al. Survival for eight major cancers and all cancers combined for European adults diagnosed in 1995-99: results for the EUROCARE study. Lancet Oncol 2007;8:773-8

26. Spada et al. PillCam Colon Capsule Endoscopy: A Prospective, Randomized Trial Comparing Two Regimens of Preparation. J Clin Gastroenterol 2010. May 11.

27. Spada et al. Meta-analysis Shows Colon Capsule Endoscopy Is Effective in Detecting Colorectal Polyps. Clin Gastroenterol Hepatol 2010 Mar.

28. Van Gossum et al. Capsule endoscopy versus colonoscopy for the detection of polyps and cancer. N Engl J Med 2009 Jul 16;361(3):264-70.

29. Sieg $A$ at al. Is PillCam COLON capsule endoscopy ready for colorectal cancer screening? A prospective feasibility study in a community gastroenterology practice. Am J Gastroenterol 2009;Apr 104(4): 848-54. 
